\title{
8
}
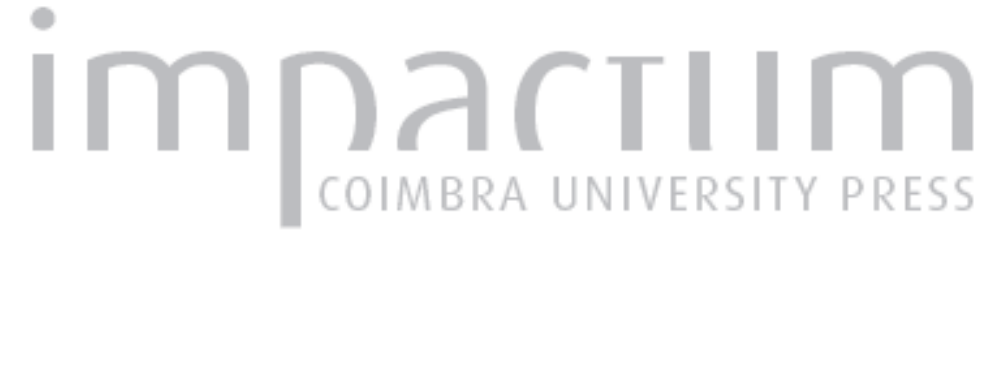

\section{[Recensão a] Fernando Cortés Cortés, La escuela en la extremadura meridional del siglo XIX}

Autor(es): $\quad$ Trindade, Sara Marisa da Graça Dias do Carmo

Publicado por: Imprensa da Universidade de Coimbra

URL persistente:

URI:http://hdl.handle.net/10316.2/43254

DOI:

DOI:https://doi.org/10.14195/0870-4147_48_18

Accessed : $\quad$ 26-Apr-2023 05:38:12

A navegação consulta e descarregamento dos títulos inseridos nas Bibliotecas Digitais UC Digitalis, UC Pombalina e UC Impactum, pressupõem a aceitação plena e sem reservas dos Termos e Condições de Uso destas Bibliotecas Digitais, disponíveis em https://digitalis.uc.pt/pt-pt/termos.

Conforme exposto nos referidos Termos e Condições de Uso, o descarregamento de títulos de acesso restrito requer uma licença válida de autorização devendo o utilizador aceder ao(s) documento(s) a partir de um endereço de IP da instituição detentora da supramencionada licença.

Ao utilizador é apenas permitido o descarregamento para uso pessoal, pelo que o emprego do(s) título(s) descarregado(s) para outro fim, designadamente comercial, carece de autorização do respetivo autor ou editor da obra.

Na medida em que todas as obras da UC Digitalis se encontram protegidas pelo Código do Direito de Autor e Direitos Conexos e demais legislação aplicável, toda a cópia, parcial ou total, deste documento, nos casos em que é legalmente admitida, deverá conter ou fazer-se acompanhar por este aviso.

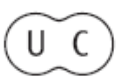




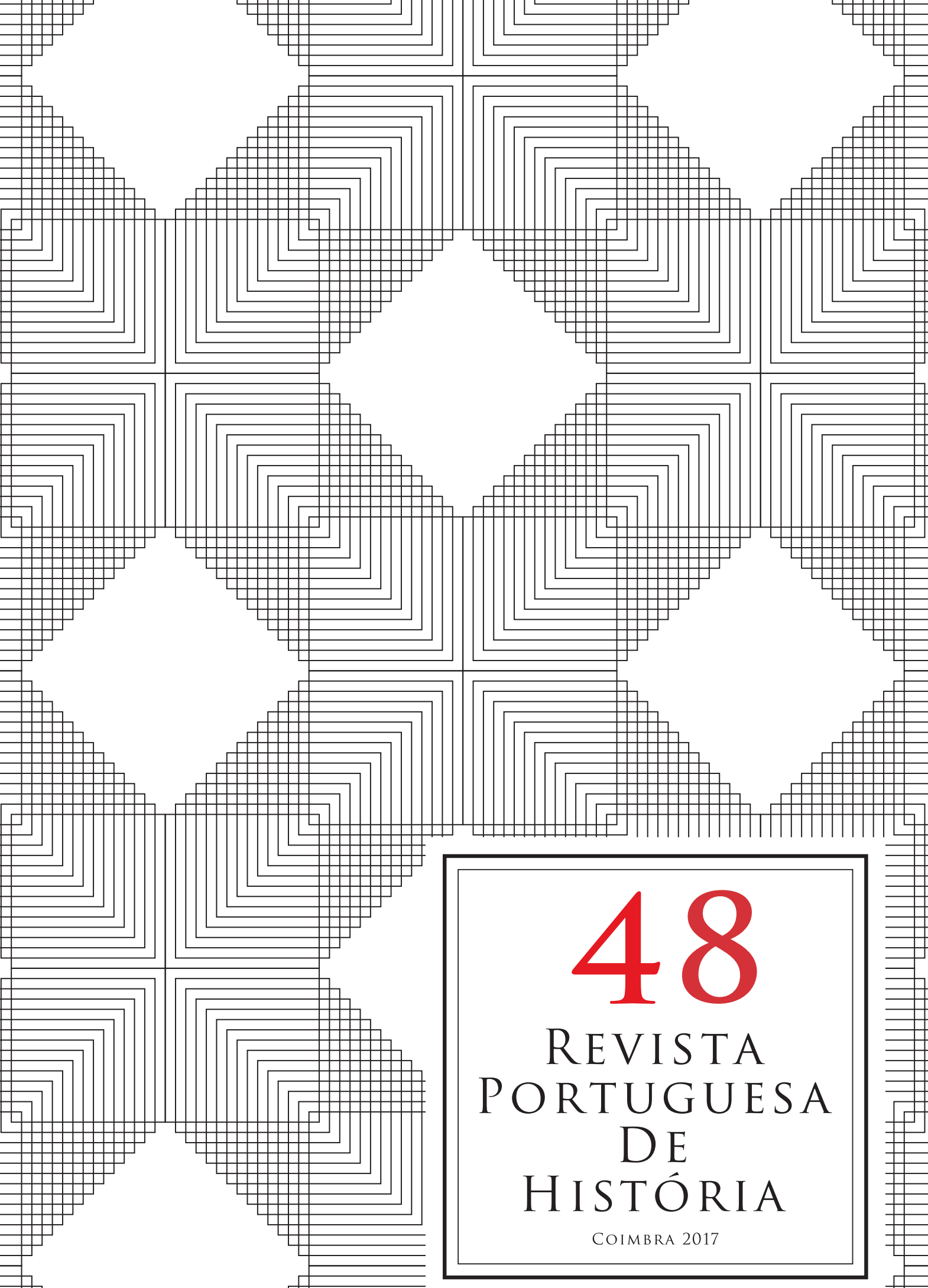




\section{Fernando Cortés Cortés, La escuela en la extremadura meridional del siglo XIX. Badajoz, Imprenta Diputación de Badajoz, 2016, 385 p.}

Fernando Cortés Cortés é professor catedrático do Bachillerato (ensino básico espanhol), Inspetor de Educação do Ministerio de Educación y de la Consejería de Educación de la Junta de Extremadura, jubilado, doutorado em história e também em pedagogia e ainda cronista da cidade de Badajoz, diretor da Revista de Estudios Extremeños de la Diputación de Badajoz.

A obra de grande fôlego aqui apresentada resulta da profunda investigação realizada pelo autor a propósito da educação primária na região da Extremadura espanhola, durante o século XIX, começando o autor por realizar, no capítulo "a modo de prólogo" (p. 5-12), uma exaustiva descrição dos trabalhos parcelares que já havia realizado e que agora, em conjunto com novas fontes documentais, colige num só trabalho. Assim, vem este livro cumprir o objetivo de "análisis y de estudio de aquelles fuentes documentales que posibilitaban la aproximación a visiones globales de la situación educativa que en el marco geográfico se podia detectar" (p. 12).

Divide o autor o trabalho em capítulos balizados temporalmente a partir de fontes documentais de importância elevada e que vêm permitir, por um lado, uma visão global e, por outro, uma análise detalhada da instrução primária na região da Extremadura, quer ao nível da instrução pública quer também um pouco da instrução feita pelas escolas privadas.

Desta forma, encontramos nesta obra seis capítulos que percorrem a situação educativa na Extremadura, entre finais do século XVIII e inícios do século XX, assentes em diferentes fontes de entre as quais se destacam: a visão dos informantes de Tomás López, "geógrafo de los Dominios de Su Magestad", de 1798, e dos interrogatórios da Real Audiencia de Extremadura; as Diligencias correspondientes al examen de Maestros de primeiras letras de Don...; o Reglamento general de instrucción pública de 1821; o Diccionario Geográfico-Estadístico-Histórico de Espanã y sus posesiones de Ultramar; a circular n. ${ }^{\circ}$ 36 de Badajoz; o Estado de la instrucción primaria de esta província en el presente año... maestros que ejercen con titulo ó sin él..., incluido no Boletín Oficial de la Provincia de 8 de janeiro de 1842; a relación de las cantidades devengadas y abonadas por descuentos de las Escuelas de la Província, de 1897; o discurso del inspector de 1. ${ }^{a}$ ensenãnza de la província de Badajoz Don Pedro Redondo y Población en el acto de la distribución de premios á los alumnos de las escuelas municipales de la capital, de 1895.

Ora, se no capítulo introdutório o autor se queixava da ausência de estudos que proporcionassem uma visão global do tema em análise, no capítulo 2 
(pp. 13-16) apresenta dois documentos que vão permitir conhecer, em primeira mão, a realidade material da região da Extremadura, no final ainda do século XVIII, e também da sua população. Neste ponto o autor explica também como era reduzida a frequência da educação primária naquela região e associada ao ensino particular, justificando-se, desta forma, o esforço que irá ser empreendido no século XIX no sentido de alargar a instrução primária, da sua universalização e gratuitidade.

Já no capítulo 3 (pp. 17-54), sobre as ações desenvolvidas no dealbar do século XIX, percebemos, através das análises realizadas pelo autor, que uma das primeiras preocupações foi para com a formação de Mestres, pretendendo-se contudo profissionais submissos quer à Igreja, quer ao Estado, pois desejava-se que fossem "<buenos cristianos $>$ y politicamente vinculados, defensores y sumisos a las estructuras gubernamentales imperantes y que, después de 1812, no ayan ni compartido ni participado en la revolucionaria ideologia del invasor francés" (pp. 24-25).

Dificuldades várias existiram para proporcionar uma boa educação nesta região (como financeiras, políticas ou mesmo qualitativas), apesar dos esforços empreendidos, e pouco ou nada se fala sobre a instrução feminina mas, de acordo com o autor, "existen síntomas inequívocos de que algo se está modificando, y de que la intensificación de la educación y el mejoramiento de las estructuras educacionales comienzan a interessar tanto a los responsables familiares como a los municipales" (p. 46).

O capítulo 4 (pp. 55-94) trata a educação pública da década de 1820, referindo-se que, com os alvores do liberalismo em Espanha, houve, entre 1820 e 1823, um grande impulso na instrução primária, sob grande influência da França "enciclopédica y revolucionária" (p. 55), concebendo-se um ensino público, gratuito e universal, de acordo com o estabelecido no Regulamento de 1821.

Sobre este período cronológico o autor apresenta um conjunto de tabelas que nos fornecem detalhada informação a propósito dos tipos de escolas existentes, seus financiamentos, instalações, professores, objetivos educativos, proporcionando ao leitor um detalhe minucioso da situação qualitativa na Extremadura espanhola na década de 1820.

O mesmo acontece a propósito da instrução primária na década de 40 , já no capítulo 5 (pp. 95-176), possibilitando, pelas informações provenientes do Diccionario Geográfico-Estadístico-Historico de España y sus Posesiones de Ultramar, de Pascual Madoz, a apresentação de variadas tabelas onde constam a população da região estremenha, pressupostos municipais, salário do secretário da educação e valores destinados à dotação de cada escola (pp. 99-105). 
A análise feita pelo autor vai permitir perceber, em relação ao volume populacional, não só a quantidade de escolas públicas existentes na década de 40 do século XIX, como também o valor com que cada escola podia contar e também se eram escolas apenas para rapazes, exclusivas para raparigas ou mistas.

Ficamos então com a percepção de que houve 9 localidades que aparentam ter tido uma maior preocupação com as necessidades educacionais dos seus jovens habitantes, mostrando "una vez más la disciminación que en estos momentos padece la educación femenina" (p. 112), sendo que as dotações médias das escolas masculinas são superiores às das femininas.

Constata ainda Cortés Cortés que, em algumas (raras) ocasiões, para além da dotação municipal, existe um sistema de financiamento misto da escola, proveniente de fundos concelhios ou de obras pias administradas pelo município (p. 113).

Através da análise da obra Estado de la instrucción primaria de esta província en el presente año... maestros que ejercen con titulo ó sin él..., incluido no Boletín Oficial de la Provincia de 8 de janeiro de 1842, o autor conclui que existe alguma semelhança entre os dados provenientes deste texto e os do trabalho de Pascual Madoz, para além de que existia ainda alguma debilidade das estruturas públicas da instrução provincial e consequente importância quantitativa das escolas privadas.

Em seguida são apresentados os locais mais favorecidos e os mais desfavorecidos do conjunto provincial, questionando-se, e respondendo devidamente, sobre os motivos que causariam essa mesma distribuição.

Quando, ainda no mesmo capítulo, o autor tenta fazer uma análise individual das realidades educativas locais, constata as dificuldades encontradas, uma vez que não existem muitos estudos sobre as essas estruturas, justificando por isso a sua escolha em fazer uma aproximação a este tema limitada à cidade de Badajoz e Jerez de los Caballeros (neste caso resultado de obra já publicada pelo autor), recorrendo novamente ao Diccionário de Pascual Madoz.

Neste ponto voltamos a receber informações acerca dos estudos femininos, mas também relativas ao material escolar, aos professores existentes e à situação educativa em Badajoz em 1844, bem como propostas de melhoria da situação educativa, que passaria pela criação de uma "escuela pública de párvulos" (p. 155), ou seja, do ensino pré-escolar e também uma análise da situação escolar dos alunos das escolas privadas.

Quando chegamos ao capítulo 6 (pp. 177-197), a propósito da situação educativa em 1859 e em 1870, encontramos uma análise relativa ao primeiro ano indicado, juntamente com uma abordagem comparativa entre estes dados e os de 1841 mas a este ponto seguem-se apenas um conjunto de tabelas relativas a 1870 sem qualquer análise feita pelo autor. 
Chegamos então aos anos finais do século XIX, tratados a partir da análise, entre outras fontes, das Quantificaciones de 1897, no capítulo 7 (pp. 197-285). Essas informações são provenientes da Relación de las cantidades devengadas y abonadas por descuentos de las Escuelas de esta província $\mathrm{e}$ que foram publicados em vários números do Boletín Oficial de la Provincia de 1898. Entende o autor que a riqueza deste documento proporciona um amplo conhecimento da situação educativa provincial dos finais do século XIX e, depois de uma análise e articulação com outras fontes, o autor chega à conclusão, mais uma vez, de que também aqui se manifesta uma infraestrutura pública educativa em melhores condições do que aquela encontrada em 1841, demonstrando-o nas tabelas apresentadas nas páginas 213 a 215 .

Destina ainda o autor alguns parágrafos a propósito das dificuldades de instalação de escolas pré-primárias (escuelas de párvulos), na região, situação ultrapassada com algum sucesso no final do século XIX.

Contudo, de acordo com as análises finais do autor, apesar de alguma legislação aprovada ao longo do século XIX tentar melhorar a situação educativa da região, verifica-se que, por um lado, se encontram municípios onde não existe o número mínimo de escolas elementares de rapazes e de raparigas e que, por outro lado, outros Ayuntamentos dispõem de mais escolas do que as definidas.

Para além disso, conclui também o autor que "parece que los habitantes de las localidades más pobladas son los que padecen mayores carencias en sus dotaciones educativas de instrucción primária pública" (p. 231), o que reduz as possibilidades de os seus habitantes terem todos o mesmo acesso à educação.

Mesmo assim, apesar de o Real Decreto de 23 de fevereiro de 1893, prever que o distrito faça o necessário para ter escolas em número suficiente em relação à população que dele faz parte, Cortés Cortés refere que desde os anos 80 que esta situação se afigura complexa e, apesar de não ser bem entendido por muitos, são feitas subvenções a escolas privadas para que recebam todos os alunos necessários.

Cortés Cortés aponta ainda uma situação que nos parece importante para entender as dicotomias entre o que são as diretivas gerais e as ações particulares dos Distritos: "por lo general, las actuaciones municipales entrevistas, los acuerdos y la toma de decisiones ligadas a la instrucción primária de cada localidad, se mueven entre, por um lado, los que parecen propósitos municipales de fomentarla y extenderla, incidiendo e intentando profundizar en la que a finales de siglo era una especifica responsabilidad de ya dilatada tradición, $y$, por otro, las dificultades económicas inherentes a esa obligación legal. Dificultades económicas acentuadas por la generalizada situación de crisis que en los momentos finales del siglo XIX parece se registra, cuando menos, en la provincia de Badajoz y de la que se hacen eco los acuerdos municipales" (p. 249). 
Segue-se então uma análise relativa às causas para as dificuldades financeiras e consequentes dívidas dos Distritos às instituições educativas ou aos próprios professores, situação essa que se encontra já nos anos 70 e que vai piorando até ao final do século.

A este propósito referem-se ainda as ideias deixadas por D. Pedro Redondo y Población, Inspetor de Instrução Primária, o qual, no seu discurso na entrega de prémios aos alunos das escolas municipais de Badajoz, em 1892, apresenta o estado da educação naquela cidade. Sobre este assunto ficam algumas notas, nomeadamente o facto de que esta situação não espelhava o que de facto acontecia na generalidade da província, e que vai mais tarde ser incluído em novo texto de Redondo y Población, datado de 1895, e onde é indicado que é necessário aumentar o número de escolas primárias e pagar com maior pontualidade os seus encargos, fazendo cumprir a Lei (p. 268). Afigura-se-nos importante destacar (apesar de Cortés Cortés assinalar o facto de Redondo y Población não citar as suas fontes) que, em 1895, 97,03\% dos homens e 95,78\% das mulheres não sabiam ler e que $72,09 \%$ dos homens e $84,40 \%$ das mulheres não sabiam escrever (p. 269).

Finaliza o autor o seu trabalho reconhecendo que, apesar da evolução positiva na província de Badajoz, esta não acompanhava a evolução nacional, reflexo provável de que as melhorias operadas não foram as suficientes.

Apesar de todas as referências documentais, de grande volume e importância, este último capítulo leva o autor a avançar e recuar no tempo, para justificar a situação em que se encontrava a província de Badajoz no final do século XIX (apresentando ainda alguns dados relativos já à primeira década do século XX). Contudo, esta fluência de texto escolhida torna difícil ter uma ideia clara dos dados que nos pretende apresentar.

Entre as palavras finais, lugar para o sentimento de obediência ao que havia planeado inicialmente apresentar: uma "panorámica global de la educación en la província de Badajoz del siglo XIX. Realidad brillante y panorámica sombría. Porque ligeramente sombrio aparece el cuadro resultante, radiografía del estado de la educación y de las instituciones educativas primarias. Y porque brilante se manifiesta el desvelo del conjunto de los maestros y de las maestras, de sus auxiliares" (pp. 282-283).

Sara Marisa da Graça Dias do Carmo Trindade

CEIS 20/ UC

sara.trindade@uc.pt 